\title{
Ocorrência de Curvularia lunata em Jurubeba no estado de Alagoas
}

\author{
Iraildes Pereira Assunção ${ }^{1}$; Gaus Silvestre de Andrade Lima ${ }^{2 *}$; Edna Peixoto da Rocha Amorim; ${ }^{1}$ \\ Maria de Fátima Silva Muniz ; Laurício Endres²
}

${ }^{1}$ Departamento de Fitotecnia e Fitossanidade, Centro de Ciências Agrárias, Campus Delza Gitaí, Universidade Federal de Alagoas. BR 104, Km 85, CEP 57100-000, Rio Largo, AL.; ${ }^{2}$ Departamento de Botânica, Centro de Ciências Biológicas, Universidade Federal de Alagoas. Praça Afrânio Jorge, S/N, Prado, CEP 57010-020, Maceió, AL.

\#Autor para correspondência: Gaus Silvestre de Andrade Lima e-mail: gausandrade@yahoo.com.br.

Data de chegada: 12/07/2004. Aceito para publicação em: 20/07/2005.

1091

\section{ABSTRACT}

Assunção, I.P.; Lima, G.S.A.; Amorim, E.P.R.; Muniz, M.F.S. Endres, L. Occurrence of Curvularia lunata on "Jurubeba" in Alagoas State, Brazil. Summa Phytopathologica, v.32, n.4, p.386-387, 2006.

\footnotetext{
"Jurubeba" (Solanum paniculatum L.), a member of the Solanaceae family, is considered a weed in several crops grown in many states in Brazil. This study reports the occurrence of the fungus Curvularia lunata (Wakker) Boedijn causing leaf spots on "jurubeba" plants in
}

the State of Alagoas. It was proved based on the Kochs's postulates that the isolate of $C$. lunata was pathogenic on "jurubeba" plants but not on plants from other solanaceous species such as tomatoes, tobacco, and pepper.

Additional keywords: diagnosis, Solanum paniculatum, solanaceous, leaf spot.

\section{RESUMO}

Assunção, I.P.; Lima, G.S.A.; Amorim, E.P.R.; Muniz, M.F.S. Endres, L. Ocorrência de Curvularia lunata em Jurubeba no estado de Alagoas. Summa Phytopathologica, v.32, n.4, p.386-387, 2006.

A jurubeba (Solanum paniculatum L.) é um membro da família Solanaceae considerada como uma importante planta invasora em vários estados do Brasil. Esse estudo relata a ocorrência do fungo Curvularia lunata (Wakker) Boedijn causando lesões foliares em jurubeba no estado de Alagoas. Com base nos postulados de Koch demonstrou-se que o isolado obtido foi patogênico a plantas de jurubeba, mas não a outras solanáceas cultivadas como tomate, fumo e pimenta.

Palavras-chave: diagnose, Solanum paniculatum, solanáceas, lesões foliares.

A jurubeba (Solanum paniculatum L.), também conhecida como fruta-de-lobo ou lobeira, é uma solanácea de porte arbustivo amplamente distribuída na América tropical (4). Aos frutos da jurubeba são atribuídas propriedades medicinais, sendo popularmente utilizados no tratamento de icterícia, da hepatite crônica e de febres (5), como também no preparo de doces e bebidas (6). No entanto, a principal importância dessa espécie é como planta invasora, ocupando os mais diversos tipos de ambientes, desde lavouras a terrenos baldios e margens de rodovias (4). À semelhança do que ocorre com outras invasoras, a jurubeba caracteriza-se por apresentar capacidade de colonização rápida de ambientes abertos (inclusive por ação antrópica) e reprodução predominantemente autogâmica, o que lhe confere alta uniformidade genética em nível populacional $(2,3,5)$.

Plantas de jurubeba apresentando lesões escuras irregulares sobre a superfície superior das folhas (Figuras 1A e 1B) foram observadas nos municípios de Rio Largo, Murici e Maceió (todos no estado de Alagoas), crescendo em terrenos baldios ou como invasoras de culturas como milho, caupi e citros. As lesões se concentravam principalmente nas folhas mais velhas, se apresentando como pequenas pontuações escuras com contornos amarelados no início de seu desenvolvimento (Figura 1A). Com o decorrer do tempo as lesões expandiram e freqüentemente coaleceram, tomando extensas áreas do limbo foliar, (Figura 1B).

$\mathrm{O}$ isolamento do agente etiológico foi realizado em BDA (batatadextrose-ágar), plaqueando-se fragmentos retirados da zona de transição das lesões com o tecido verde. Verificou-se o crescimento de um fungo com micélio cotonoso, de tonalidade cinza claro, que tomou toda a placa de Petri ( $9 \mathrm{~cm}$ de diâmetro) em cerca de cinco a seis dias. Com o decorrer do tempo, o micélio adquiriu uma tonalidade mais escura, quase preta.

Observações ao microscópio ótico revelaram que o fungo produzia conídios de coloração escura sobre conidióforos livres. Os conídios apresentavam três septos, sendo o central tipicamente não mediano, com a segunda célula mais larga e escura que as demais; conídio curvado nesta célula (Figura 2) com dimensões médias de 20,6 + $2,9 \mu \mathrm{m} \times 8,5+1,1 \mu \mathrm{m}$. Considerando-se a sintomatologia, o aspecto 


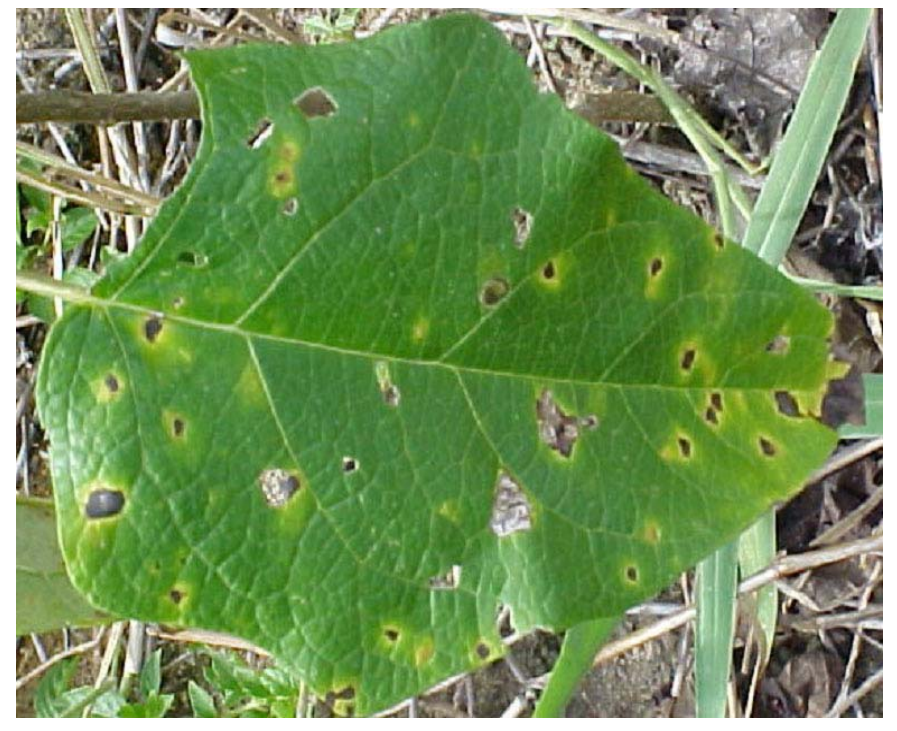

A

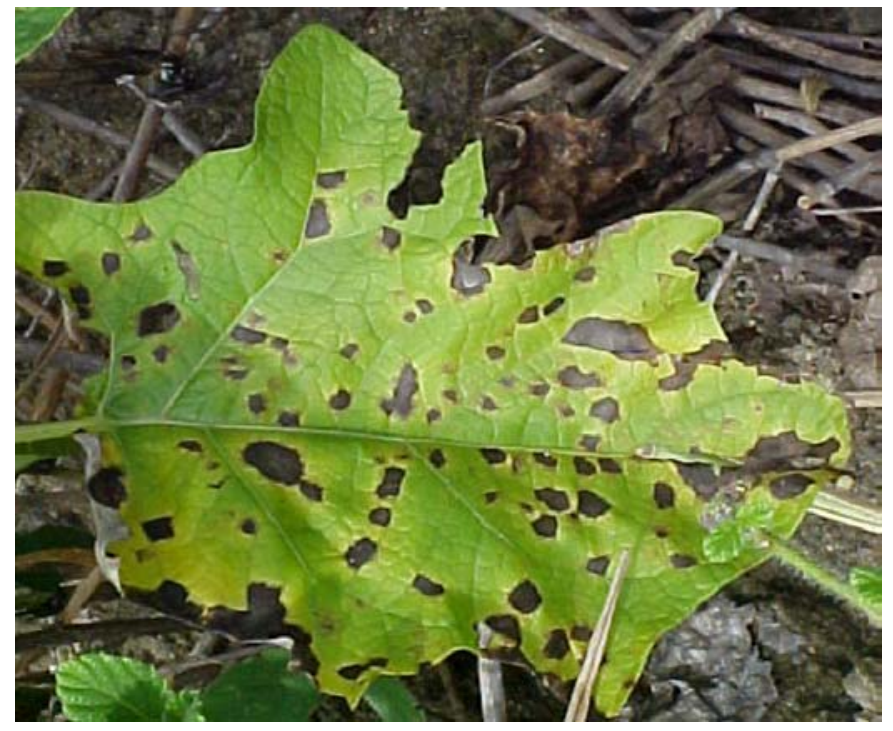

B

Figura 1. Lesões provocadas por Curvularia lunata sobre folhas de jurubeba. A - lesões na fase inicial do desenvolvimento, apresentando um halo clorótico. B - lesões mais desenvolvidas conferindo à folha um aspecto de crestamento.

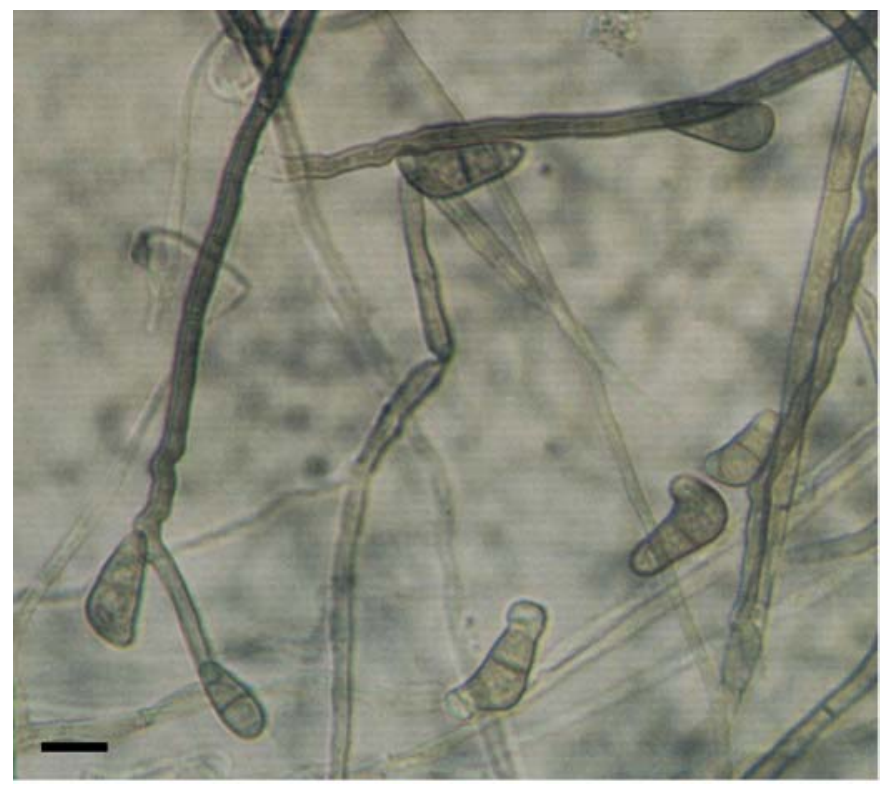

Figura 2. Conídios e conidióforos produzidos "in vitro" por Curvularia lunata isolado da jurubeba. (Barra $=10 \mu \mathrm{m})$

da cultura em BDA e a morfologia dos conídios, o fungo foi identificado como Curvularia lunata (Wakker) Boedijn, conforme a descrição de Ellis (1).

O teste de patogenicidade foi realizado em plantas de jurubeba cultivadas em vasos plásticos com capacidade para $2 \mathrm{~L}$ em condições de casa de vegetação. A inoculação foi realizada mediante deposição de um disco de BDA contendo estruturas do fungo sobre folhas de jurubeba. Adicionalmente, empregando-se a mesma metodologia, também foram inoculadas plantas de fumo (Nicotiana tabacum L.), tomate
(Lycopersicon esculentum Mill.) e pimenta (Capsicum frutescens L.). A deposição de um disco de BDA sobre folhas das referidas espécies consistiu no controle negativo do experimento. Todas as plantas foram mantidas em câmara úmida durante 48 horas. Lesões semelhantes às observadas em campo foram evidenciadas em plantas de jurubeba a partir de seis dias após a inoculação. O patógeno foi reisolado das plantas inoculadas e a análise microscópica revelou estruturas idênticas às originais, completando-se os postulados de Koch. Nas condições utilizadas o isolado obtido não se mostrou patogênico a outras solanáceas de importância econômica como fumo, tomate e pimenta. Esse aparentemente é o primeiro registro de C. lunata causando lesões foliares em jurubeba no Brasil.

\section{REFERÊNCIAS BIBLIOGRÁFICAS}

1. Ellis, M.B. Dematiaceous hyphomycetes. Kew: Commonwealth Mycological Institute, 1971. 608 p.

2. Forni-Martins, E.R.; Marques, M.C.M.; Lemes, M.R. Biologia floral e reprodução de Solanum paniculatum L. (Solanaceae) no estado de São Paulo, Brasil. Revista Brasileira de Botânica, São Paulo, v.21, n. 2, p. 117-124, 1998.

3. Grant, V. Genetics of flowering plants. New York: Columbia University Press, 1975. 514p.

4. Leitão-Filho, H.F.; Aranha, C.; Bacchi, O. Plantas invasoras de culturas no estado de São Paulo. São Paulo: Hucitec \& Agiplan, 1975. v. 2, 300p.

5. Pio-Corrêa, M. Dicionário das plantas úteis do Brasil e das exóticas cultivadas. Rio de Janeiro: Ministério da Agricultura, IBDF, 1969. v. 4,765 p.

6. Zurlo, C.; Brandão, M. As ervas comestíveis: descrição, ilustração e receitas. São Paulo: Globo, 1990. 167p. 